DEPARTAMENTO DE ANATOMA I'ATOLOGICA

Dirctor: Prof. 1)r. Euclydes Onofre Martins

\title{
NÍVEIS NORMAIS DE OXALEMIA EM ANIMAIS DOMÉSTICOS
}

(NORMAL OXALIC ACID BLOOD LEVELS IN DOMESTIC ANIMALS)

J. A. Solza

Prof. Assistente Doutor

\author{
Etclydes ONOFRE M.IRTINS
}

Prof. Catcdrático

\section{INTRODUCX̃O}

A toxicodinâmica do ácido oxálico é bem conhecida, tanto para o homem como para os animais domésticos $(10,12,13$ e 15). Os herbivoros particularmente, apresentam maior possibilidade de intoxicação crônica por êsse agente quimico. No homem, a intoxicação é rar'a, devido principalmente, ao sabor desagradável dêsse ácido orgânico. Quando ocorre, é quase sempre acidental, podendo provocar a morte ràpidamente com doses minimas (3 e 13). A intoxicação crônica em herbivoros de interêsse zootécnico, tem sido referida por alguns autores (1), como resultante da ingestão frequiente de vegetais ricos em ácido oxálico. Entre os animais domésticos monogástricos, sobretudo cão e gato (10), a ocorrência da intoxicacão, via de regra, é aguda, tanto acidental como intencional.

GLockNer (.)), estudando a ocorreencia da hematúria na Saxônia, atribui a hiperoxalemia encontrada entre os animais comprometiclos, a natureza da alimentação ingerida, como o principal agente etiológico da doença. HADwes (7), reproduziu experi-

- Quimica. Fstagiála da Disciplina de Blofisten da Faculdade de Ciências Méc. dicas e Biologicas de Botucatu - Prof. J. A. Souza.

* Médico Veterinário. Seccão de Bloquímica e Farmacodinâmica do Instituto Biolöglco de São Patulo. 
mentalmente na espécie afetada o quadro da hematúria, através de infusōes vesicais de soluções de ácido oxálico. Segundo êste autor, o ácido oxálico em contacto com a urina, formaria o oxalato de cálcio, capaz de desenvolver uma ação irritante na mucosa vesical. Utilizando a via oral, conseguiu reproduzir o quadro clínico da hematúria. Schleger. (11), por sua vez considera que as quantidades de ácido oxálico que naturalmente o animal recebe com a alimentação é incapaz de provocar o quadro clínico da hematúria. Para GeorgitrF (4), a hematúria enzoótica dos bovinos ć uma toxicose e nāo uma doença carencial. Galtier, citado por Mello (8). atribui o aparecimento da hematúria enzoótica dos bovinos, à presença de agentes tóxicos contidos em plantas ingeridas pelo gado. DatTa (2), ao referir aos prováveis fatōres etiológicos da hematúria dos bovinos, dentre outros, refere-se ao teor de ácido oxálico contido em certos vegetais ingeridos pelo gado. WatTs (16), administrando pequenas doses de ácido oxálico à carneiros, verificou que a uréia, calcemia e tensão de gás carbônico, aumentaram significantemente. Por outro lado, apenas pequenissimas quantidades de ácido oxálico foram encontrados nos tecidos pelo exame toxicológico "post-mortem". Talapatra e colaboradores (14), demonstraram que o oxalato de cálcio, não é formado no rumem do bovino em presença do cálcio livre, porém, com o cálcio contido nos alimentos, passando para as fezes sob a forma de oxalato de cảlcio.

O conhecimento dos niveis normais de um ou mais componentes bioquimicos, entre animais pertencentes à espécies envolvidas em processos patológicos que reclamam esclarecimento etiológico, represerta quesito indispensável ao estudo do quadro nosológico, bem como na conduta terapêutica e profilática.

Levantamento bibliográfico, revelou a inexistência de trabalho nacional, relacionando niveis normais de oxalemia entre animais de interêsse médico veterinário.

No presente estudo, procuramos estabelecer os niveis sćricos normais da ácido oxálico, em algumas espécies de animais domésticos de interêsse médico veterinário, tendo em vista o valor prático representado pela normoxalemia no estudo da intoxicação oxálica anımal.

\section{MNTERIAI, F METODOS}

Utilizamos amostras de sangue recolhidas de seis espécies animais, distribuidas conforme a tabela I, perfazendo um total de 156 animais estudados. Os animais foram distribuidos em três grupos, respectivamente: $\Lambda, \mathrm{B}$ e $\mathrm{C}$. No grupo $\mathrm{A}$, reunimos 26 felinos 
e 30 suinos; no grupo $B, 30$ bovinos e 26 bubalinos e, finalmente no grupo C, 25 caninos e 19 eqüinos, tabela II. Os animais estudados pertenciam a ambos os sexos, com exceção dos eqüinos que pertenciam anenas ao sexo feminino, e, raça PSI, enquanto que, os demais animais, de raça não definida.

Os bovinos, suínos e bubalinos, escolhidos ao acaso entre os animais encaminhados ao Matadouro Municipal de Botucatu, todos adultos e aparentemente gozando boa saúde. Os felinos e caninos, adultos, aparentemente sadios, pertencentes ao Biotẻrio Central da Faculdade de Ciências Médicas e Biológicas de Botucatu. Os eqüinos PSI, adultos, aparentemente sadios, pertencentes a $\mathrm{Ha}$ ras, localizado no municipio de Botucatu. Os felinos e caninos foram sangrados por punção cardiaca, enquanto que os suinos, por punçāo da cava anterior e os bovinos, bubalinos e eqüinos, por punção da jugular. Todos os animais submetidos an estudo, foram mantidos em jejum de 24 horas antes da punção.

As amostras de sangue foram recolhidas em tubos de vidro scecos e limpos, conservados à temperatura ambiente até a coagulaçāo e obtenção do sôro. O sôro sangüinco, separado do coágulo por aspiração, centrifugado e conservado em refrigerador a $5^{\circ} \mathrm{C}$, para posterior doseamento quimico.

A determinação do ácido oxálico foi executado pela técnica de Merz e Maugeri (9). Os resultados, submetidos a análise estatistica, comprendendo análise de variança e contrastes entre médias pelos testes de Duncan e Scheffẻ.

\section{RESULTAIOS}

Os valores em $\mathrm{mg} \%$ de ácido oxálico obtido nas análises químicas praticadas entre os componentes das espécies animais escolhidas, encontram-se representadas na figura 1. Foram executados um total de 156 doseamentos, distribuidos conforme tabela I.

Das amostras analizadas, 71 pertenciam a animais do sexo masculino e $8 \tilde{5}$ a animais do sexo feminino, tabela I. Os valores individuais dos animais pertencentes aos grupos estudados, encontram-se relacionados na tabela II.

Os resultados obtidos, foram analisados estatisticamente pelo Dr. Messias C. Galvão Gomes, pertencente a cadeira de Higiene e Saúde Pública da Faculdade de Medicina Veterinária da Universidade de São Paulo e, encontram-se reproduzidas na tabela III. 
TABELA I - Distribuição por sexo dos animals estudados

\begin{tabular}{|l|c|c|c|}
\hline \multirow{2}{*}{ Espécie animal estudadic } & \multicolumn{2}{|c|}{ Sexo } & \multirow{2}{*}{ Total } \\
\cline { 2 - 4 } & Masculino & Femenino & \\
\hline Felis dlomestica & 16 & 10 & 26 \\
Sus scrofa domestical & 13 & 17 & 30 \\
Bos laurus va. inclicus & 24 & 6 & 30 \\
Bubalus bubalis & - & 26 & 26 \\
Canis familiaris & 18 & 7 & 25 \\
Equus caballus & - & 19 & 19 \\
Total geral & 71 & 85 & 156 \\
\hline
\end{tabular}

\section{DISCUSS $\Lambda ̄ O$}

O estudo estatístico da oxalemia entre algumas espécies de animais domésticos, revelou que êsses animais, apresentam no sangue circulante, valores de ácido oxálico que diferem significantemente, permitindo agrupá-los conforme os indices de oxalemia apresentado, tabela III.

Neste estudo, a oxalemia encontrada nos animais pertencentes ao grupo $A$, difere significantemente dos animais agrupados em $B$ ao nivel de $1 \%$, quando analisados pelo teste de Scheffé. Por outro lado, a oxalemia dos animais do grupo $B$, difere signicantementa do grupo $C$, ao nivel de $1 \%$ quando se aplica o mesmo teste.

A superfície corporal das espécies animais estudadas não interferiu nos resultados de doseamento do ácido oxálico sangüineo.

Os resultados obtidos, permite-nos admitir que as oscilaçōes da oxalemia para cada espécie animal estudada, estejam na dependência do metabolismo intermediário de cada espécie e, talvez no tipo alimentar. Nos poligástricos a maior quantidade de oxalato é decomposta pela ação bacteriana do rumem e, o fator primário no envenenamento sub-agudo é representado pela queda da calcemia e disfunção do $\mathrm{pH}$ do rumen (1).

O conhecimento da normoxalemia dos animais domésticos, é de alto significado prático no diagnóstico laboratorial, quando o 


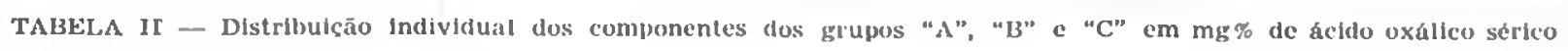
Grupos

\begin{tabular}{|c|c|c|c|c|c|c|c|c|c|c|c|}
\hline \multicolumn{4}{|c|}{ "A" } & \multicolumn{4}{|c|}{ "B" } & \multicolumn{4}{|c|}{ "C" } \\
\hline \multicolumn{2}{|c|}{ Fells (Inmestica } & \multicolumn{2}{|c|}{$\begin{array}{l}\text { Sus scrofa } \\
\text { domestica }\end{array}$} & \multicolumn{2}{|c|}{$\begin{array}{c}\text { I3os taurus } \\
\text { varletas indicus }\end{array}$} & \multicolumn{2}{|c|}{ Bubalus bubalis } & \multicolumn{2}{|c|}{ Canis famlliaris } & \multicolumn{2}{|c|}{ Equus caballus } \\
\hline$\underset{x: 0}{\operatorname{Animal}}$ & $\begin{array}{l}\text { mg\% de } \\
\text { ácido } \\
\text { oxálico }\end{array}$ & $\underset{N \times \circ}{\text { Animal }}$ & $\begin{array}{l}\mathrm{mg} \% \text { de } \\
\text { ácido } \\
\text { oxálío }\end{array}$ & $\underset{\substack{\text { Animal } \\
\text { N.o }}}{ }$ & $\begin{array}{l}\text { mg\% de } \\
\text { ácldo } \\
\text { oxálico }\end{array}$ & $\begin{array}{l}\text { Animal } \\
\therefore \times 0\end{array}$ & $\begin{array}{l}\text { mg\% de } \\
\text { ácido } \\
\text { oxálleo }\end{array}$ & $\underset{x=0}{\operatorname{Anlmal}}$ & $\begin{array}{c}\text { mg\% de } \\
\text { ácido } \\
\text { oxálico }\end{array}$ & $\begin{array}{c}\text { Animal } \\
\therefore \therefore 0\end{array}$ & $\begin{array}{l}\text { mg\% de } \\
\text { ácldo } \\
\text { oxálico }\end{array}$ \\
\hline$I$ & 14,76 & 27 & 12,60 & 57 & 10,26 & 87 & 12,42 & 113 & 4,50 & 138 & 8,10 \\
\hline 2 & 15,22 & $2 s$ & 10,80 & 58 & 10,44 & 88 & 9,90 & 114 & 6,66 & 139 & $3,60)$ \\
\hline 3 & 15,30 & 29 & 11,16 & 59 & 9.72 & 89 & 7,20 & 115 & 5,58 & 140 & 5,76 \\
\hline 4 & 10,44 & 30 & 12,24 & 60 & 10,98 & 90 & 6,30 & 116 & 4,86 & 141 & 4,32 \\
\hline 5 & 11,88 & 31 & 15,48 & 61 & 14,76 & 91 & 5,40 & 117 & 8,10 & 142 & 6,12 \\
\hline 6 & 11,70 & 32 & 12,42 & 62 & 13,50 & 92 & 5,60 & 118 & 7,20 & 1.43 & 6,66 \\
\hline 7 & 17,46 & 33 & 19,62 & 63 & 15,48 & 93 & 11.88 & 119 & 7,56 & 14.4 & 3,60 \\
\hline 8 & $.16,56$ & 34 & 10,26 & 6.1 & 11.70 & 94 & 12,06 & 120 & 5,40 & 115 & 7,38 \\
\hline 9 & 10,80 & 35 & 18,90 & 65 & 10,80 & 95 & 12,96 & 121 & 6,84 & 116 & 6,48 \\
\hline 10 & 12,42 & 36 & 13,68 & 66 & 9.18 & 96 & 18,18 & 122 & 3.78 & 147 & 8,10 \\
\hline 11 & 11,22 & 37 & 18,18 & 67 & $8,6 \cdot 1$ & 97 & 7,02 & 123 & 5,04 & 1.48 & 3,06 \\
\hline 12 & 10,43 & 38 & 8,10 & 68 & 12,96 & 98 & 13,50 & 124 & 5,94 & 1.19 & 2,70 \\
\hline 13 & 12,40 & 39 & 14,04 & 69 & 15,12 & 99 & 7,92 & 125 & 6,$66 ;$ & 150 & 6,12 \\
\hline 14 & 12,00 & 40 & 22,68 & 70 & 8,28 & 100 & 11,52 & $12 t$ & $5,7 t i$ & 151 & 3,78 \\
\hline 15 & 15,00 & 41 & 13,14 & 71 & $15,8.1$ & 101 & 13,14 & 127 & 7,56 & 152 & 9,90 \\
\hline 16 & 15,20 & 12 & 8,82 & 72 & 12,78 & 102 & 10,08 & 128 & $5,5 \mathrm{~s}$ & 153 & 5,22 \\
\hline 17 & 13,00 & .13 & 7,56 & 73 & 12,06 & 103 & 11,70 & 129 & 7,38 & 154 & 11.16 \\
\hline 18 & 13,20 & 44 & 10,80 & 7.1 & 8,82 & 104 & $8, \times 2$ & 130 & 5,01 & 155 & 6,30 \\
\hline 19 & 12,80 & 45 & 10,26 & 75 & 9,36 & 105 & 11,70 & 131 & 6,84 & 156 & 2,52 \\
\hline 20 & 13,10 & 46 & 15,84 & 76 & 6,30 & 106 & 11.34 & 132 & 8,10 & & \\
\hline 21 & 13,50 & 47 & 17,10 & 77 & 7,38 & 107 & 7,56 & 133 & 4,50 & & \\
\hline 22 & 12,90 & 48 & 13,50 & 78 & 13,14 & 108 & 7,20 & 134 & 7,38 & & \\
\hline 23 & 12,70 & 49 & $10,4-4$ & 79 & 6,66 & 109 & 6,66 & 135 & 10,98 & & \\
\hline 24 & 13,00 & 50 & 7,56 & 80 & 12,64 & 110 & 8,72 & 136 & 3,78 & & \\
\hline 25 & 13,20 & 51 & 7,92 & 81 & 9,36 & 111 & 6,48 & 137 & 7,20 & & \\
\hline 26 & 14,00 & 52 & 12,64 & 82 & 7,92 & 112 & 10,44 & & & & \\
\hline & & $\begin{array}{l}53 \\
54\end{array}$ & $\begin{array}{l}8,46 \\
6,30\end{array}$ & $\begin{array}{l}83 \\
84\end{array}$ & $\begin{array}{r}13,50 \\
8,46\end{array}$ & & & & & & \\
\hline & & 55 & 10,26 & 85 & $\begin{array}{l}0,70 \\
7,02\end{array}$ & & & & & & \\
\hline & & 56 & 7,76 & 86 & 9,90 & & & & & & \\
\hline
\end{tabular}




$$
\text { Inponoc: }
$$


objetivo é esclarecer quadros tóxicos, cuja suspeita etiológica recai sôbre intoxicação oxálica. A determinaçāo da oxalemia, deverá ser sempre acompanliada dos valores da calcemia, que mantém-se em relaçāo inversamente proporcional, nos quadros tóxicos.

TABELA III - Análise estatfstica dos resultados obtidos na determinacão da oxalemia em animais clomésticos

Análise da Variancia

\begin{tabular}{|c|c|c|c|c|}
\hline Fonte de variaceno & g. 1 . & S.Q. & Q.M. & r. \\
\hline Fntre espécles: & 5 & 1113,8103 & 222,7621 & 28,20 \\
\hline Dentro espos jess & 150 & 1181,1372 & $7, \$ 712$ & $\begin{array}{l}\text { (Sinffican- } \\
\text { te an nevel } \\
\text { de } 1 \% \text { ) }\end{array}$ \\
\hline Total & 155 & 22919.175 & - & \\
\hline
\end{tabular}

S.Q. Total $=17904.34$ s9 $-15409.4014=2294,9175 ;$ s.Q. Tratamento $=16723,2117$ - 15609.4014 = 1113.8103. Os contrastes verifloados entre ás médias foram as seguintes. Grupo $A-$ Follino $x_{1}=13,24$ : sulno $x_{2}=12,28$. Diferença não signifirativa atos niveis de $1 \%$ e $5 \%$, pelo teste de Duncan. Cirvpo $B-$ Bovino $\gamma_{3}=10,77$;

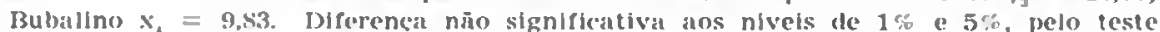

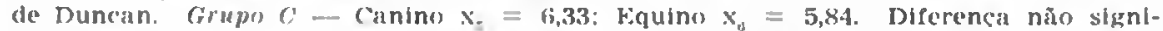
ficante aos niveis de $1 \%$ e $5 \%$, pelo teste Duncan. Cirupo "A" - Idfere significa-

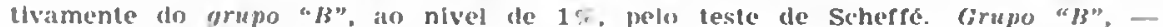
Difere signifiativamente do grupo "C" ao nivel de $1 \%$, pelo teste de scherfé.

\section{SUMÃRIO}

Os autores realçam a importância do ácido oxảlico em toxicologia. Discutem as vias metabólicas e as possiveis intoxicações acidentais $e$ intencionais em veterinária e medicina humana. Saliertam a inexistência na bibliografia nacional de trabalhos que relacionem a normoxalemia $e$ as espécies animais. Promovem o doseamento do ácido oxálico, pelo método de Mer'z e Maugeri, no sangue de 156 animais domésticos, distribuidos entre 6 espécies diferentes. Analisam estatisticamente os resultados obtidos. Concluem pela existência de valores de oxalemia que diferem significantemente ao nivel de $1 \%$, quando submetidos ao teste de Scheffé, os animais pertencentes aos grupos $A, B$ e $C$.

\section{SUMMARY}

The authors stress the toxicological importance of oxalic acid. 'They discuss the metabolic pathways and the possible accidental 
and intentional intoxications in veterinary and human medicine. They point out the inexistence, in national bibliography, of works that relate normoxalemy and animal species. Determinations of oxalic acid have been carried out, by the method of Merz and Maugeri, in the blood of 156 domestic animals belonging to six different species. The results obtained have been analysed statistically. The authors have concluded in favour of the existence of oxalemic values that significantly differ at a $1 \%$ level when comparing the results obtained after submitting the animals of groups $\mathrm{A}, \mathrm{B}$ and $\mathrm{C}$ to the test of Scheffé.

\section{REFERENCIAS BIBLIOGRAFICAS}

1. ANNISON, E. F. \& LEWIS, D. - 1962 - Metabolism in the rumen. London, Methuen \& Co. Ltd.

2. IDATTA, C. C. A. -- 1954 -- The etiology of enzootic bovine haematuria. Part I. Indian J. vet. Sci., 4:341-361.

3. DUBOIS, K. P. \& GEILING. E. M. K. - 1959-Texthook of toxicology. New York, Oxford University Press.

4. GEORGIEFF, R. - 1964 - Chronic bovine hacmaturia. Is2. Inst. éksp. vet. Med. B. A. N., 2:185-194.

5. GLOCKNER, R. - 1957 - Klinische und chemische Untersuchunger über die chronische vesikale Hamaturie der Runder. Wien. tierärstl. Mschr., $44(2): 78-88$.

6. GRIMBER, J. - 1952 - Higado, diagnostico funcional y tratamiento de la insuficiencia hepática. São Paulo, Oficinas gráficas Saraiva S.A.

7. HADWEN, W. - 1959-Dio haematurie vesicalis bovis chronica. Dtsch. tierurztl. Wschr., 66:622-682.

8. Mello, M. J. - 1929 - Hemaluria essencial dos bovinos. Rev. Ind. anim., 1(1):37-39.

9 MFRZ, W. \& MAUGFRI, S. - 1931 - Utber das Vorkommen und die bestimmung der Oxalsäure in Blüt. Zeit. Physiol. Chem., $201: 31$.

10. RADFLLFFF, R. D. - 1964 - Veterinary toxicology. Philadelphia, Lea \& Fcbiger.

11. SCHLEGEL, M. - 1934 - Die Stallrokrankcheit der Rindes (Haematuria chronica bovis). Müch. tierärıtl. Wschr., $85: 365-371,389-393,404-$ $408,416-421$.

12. SCHVARTSMAN, S.; ARAUJO, J.; MARCONDES, E. - 1965 - Aspectos pediatricos das principais intoxicacões por plantas em São Paulo. Pediat. prót., Sâo Paulo, $36: 23-34$.

13. STEWART, C. P. \& STOLMAN, A. - 1961 - Toxicology. New York, Academic Press.

14. TALAPATRA, S. K.; RAY. S. C.; SFN, K. C. - 1954 - Chronic bovine hamaturia. J. Agric. Sci, $38: 2-163$.

15. WATTS, P. S. - 1959 - Effects of oxalic acid ingestion by sheep. J. Agric. Sci, 52:2. 